\title{
Basic Study of Laser Direct Joining for CFRTP and Metals using High Power Diode Laser
}

\author{
Su-Jin Lee, ${ }^{*}$, Jong-Do Kim** and Jeong SUH* \\ *Korea Institute of Machinery \& Materials, Busan, 46744, Korea \\ **Korea Maritime and Ocean University, Busan, 49112, Korea \\ †Corresponding author : leesj@kimm.re.kr \\ (Received June 12, 2019 ; Revised July 2, 2019 ; Accepted August 16, 2919)
}

\begin{abstract}
The laser direct CFRTP-Metal joining process is performed without melting the metal surface, which is directly irradiated by a laser beam using a diode laser. The bonding properties of the process were studied without using an intermediate material such as glue. The surface temperature of the metal was measured by pyrometer during processing. The joining properties were studied based on changes in surface temperature, and a pressing force applied by a pressurization jig system, while laser power output was controlled in real time. As a result of this study, the optimum temperature and pressing force were found that would ensure good bonding performance between CFRTP and metal joints using a surface temperature control system.
\end{abstract}

Key Words : Carbon fiber reinforced thermoplastic (CFRTP), Metal, High power diode laser, Surface temperature, Laser direct joining

\section{Introduction}

Carbon Fiber Reinforced Plastics (CFRP) is a lightweight material that is widely used in a variety of applications due to its durability, high corrosion resistance and high strength characteristics compared to the mass. These features make them suitable for use on aircrafts and wings, lightweight cars, sporting goods and other mechanical devices. Thermoplastic CFRP has attracted much attention as it is capable of post-molding and post-use recycling compared to conventional thermosetting CFRP which has been studied and used. However, the strength of thermoplastic materials is still lower than that of thermosetting materials, and researches on polymer materials are underway.

However, if thermoplastic CFRP(CFRTP) materials sufficient for industrial use are developed, it is clear that environmental and cost factors will replace many of the currently used thermosetting CFRPs. Therefore, CFRP manufacturing process should be studied from a variety of perspectives. In this study, we have developed a laser direct bonding process that utilizes CFRTP character- istics and investigated the mechanical properties of the laser direct joining area.

The mechanism of laser direct joining of plastic materials is as shown in Fig. $1^{1-3)}$. First, there is a method in which the laser is focused on a metal surface from the top of a transparent plastic, and only the plastic part is melted and bonded as shown case $\mathrm{A}^{1,3)}$.

The second is a method of joining plastic parts by heat transfer by irradiating the metal surface side in the case of a plastic material which is colored or difficult to transmit $^{1,2}$. When CFRP placed on metal, the laser beam

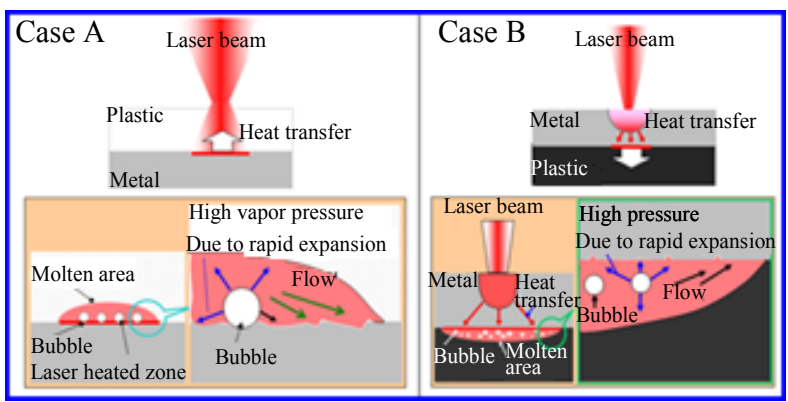

Fig. 1 Mechanism of laser direct joining of plastic and metal $^{1-3)}$ 
could not penetrate to the metal surface like 'case A'. Therefore the 'case B' method was used the CFRTP and metal laser direct joining in this study ${ }^{1-5)}$. In this paper, the process of melting the plastic material of CFRTP without melting the metal surface using an high-power diode laser and bonding properties were studied without using the intermediate material such as adhesives bond (glues).

Particularly, the surface temperature of metal was measured by pyrometer during processing and studied the joining properties according to temperature change and pressing force by pressurization jig system while maintaining constant surface temperature through laser power output control in real time. Previously, many researchers have been studying after sufficient jig fixing, considering that the higher the amount of pressure, the higher the bonding force. In this study, the effect of pressure on the bond strength was evaluated, which revealed the effect of constant pressing force on the bond strength. In this study, the effect of pressure on the bond strength was evaluated, which revealed the effect of constant pressing force on the bond strength. As a result of this study, it was possible to bond directly with CFRTP and metals without melting the metal surface. In addition, the optimum temperature and pressing force were found to be good for the bonding performance of each material through surface temperature control.

\section{Materials and Experimental Method}

The materials used in this experiment were commercially available STS306L and CFRTP whose sheets were $2 \mathrm{~mm}$ thick, $25 \mathrm{~mm}$ wide and $750 \mathrm{~mm}$ long. Austenitic stainless steels has about $1390^{\circ} \mathrm{C}$ of melting point. Table 1 shows physical properties of the polycarbonate (PC) polymer used to make the thermoplastic composite using carbon fiber.

Thermoplastics are polymers that has a linear structure and when heated becomes plastic without changing chemically. Thermoplastic are amorphous or semi-crystalline and can be heated to a ductile state and re-turn as hard plastic several times. Therefore Thermo-plastic CFRP is recyclable through the re-melting property ${ }^{6}$.

Thermoplastics can be softened by heating only with reversible changes, until temperature not reached to

Table 1 Material properties of resin for CFRTP

\begin{tabular}{|c|c|}
\hline Material & Polycarbonate(PC) \\
\hline Glass transition temperature & $145^{\circ} \mathrm{C}$ \\
\hline Melting temperature & $255 \sim 316^{\circ} \mathrm{C}$ \\
\hline Amorphous density at $25^{\circ} \mathrm{C}$ & $1.20 \mathrm{~g} / \mathrm{cm}^{3}$ \\
\hline
\end{tabular}

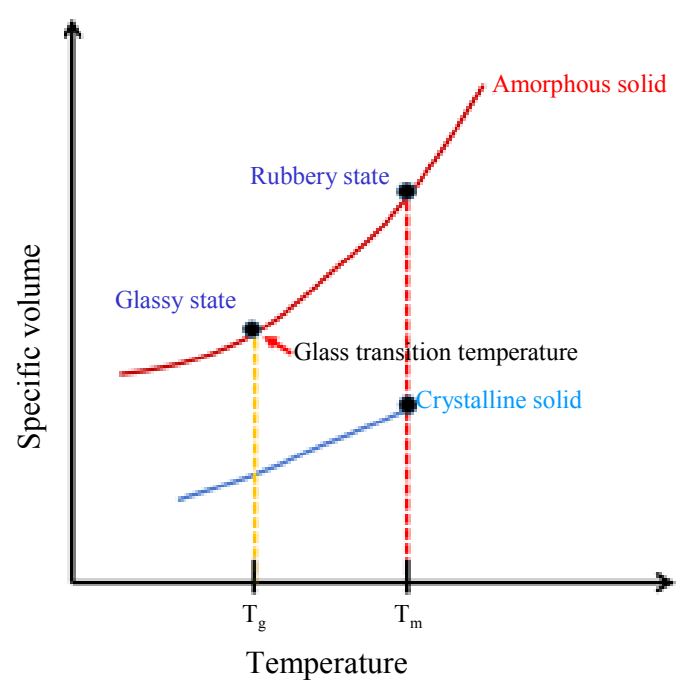

Fig. 2 Specific volume graph by temperature change of amorphous and crystalline solid

thermal decomposition point. This provides a major advantage for thermoplastics when it comes to molding or thermoforming products. A simplified graph of thermoplastics deformability as a result of temperature change is described in Fig. 2. Tg indicates glass transition temperature whereas $\mathrm{Tm}$ denotes melting temperature. Glass transition temperature is the temperature at which higher molecular weight polymers transforms from glassy state to a viscous and rubbery state which is favorable to heat bonding.

Especially in this study, plain woven type CFRTP as shown Fig. 3 was used as a main specimen. Carbon fi-

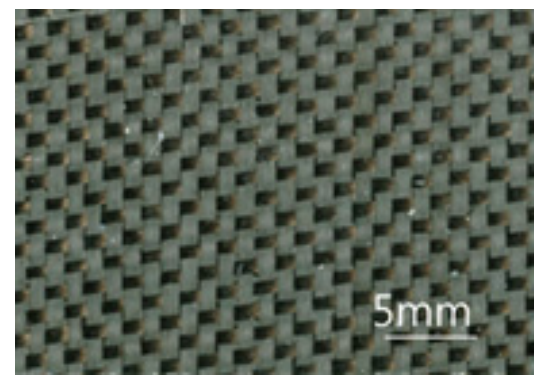

(a) Surface of plain woven type CFRTP

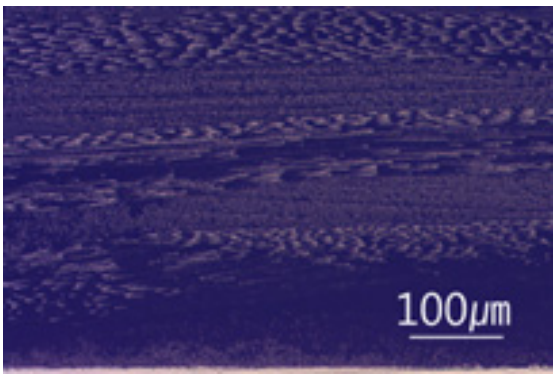

(b) Cross sectional image plain woven type CFRTP

Fig. 3 Material photographs of CFRPT used in this study 


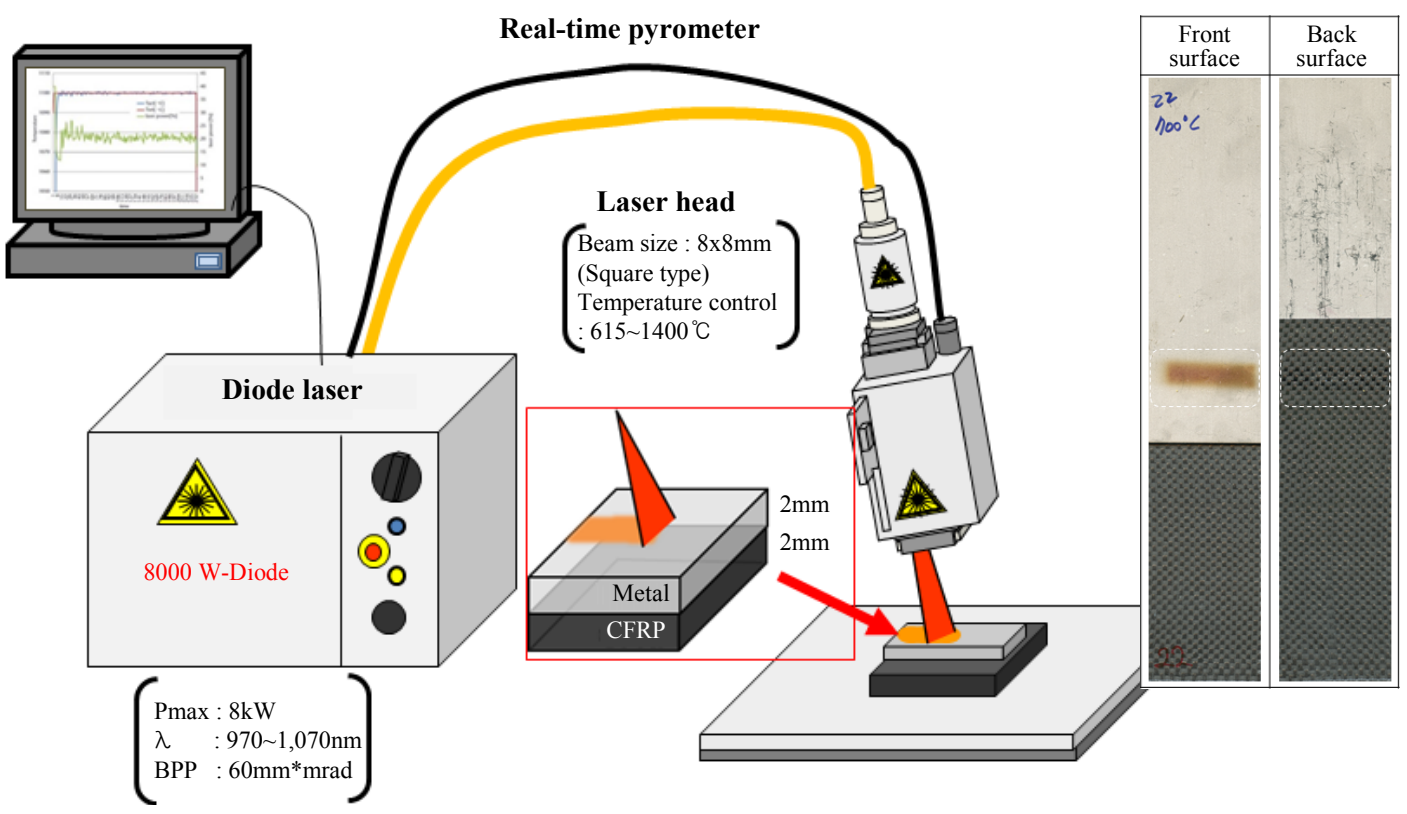

Fig. 4 Schematic experimental setup for laser direct CFRTP-metal joining using high power diode laser

ber is woven which shows a unique pattern in cross section observation. The circular shape is a part of the carbon fiber cut vertically, and the irregular linear shape can be judged as a part cut almost horizontally.

Fig. 4 shows a schematic experimental apparatuses and welding situation for direct dissimilar joining of CFRTP and metals. Lapped CFRTP and STS316L sheets were fixed to a jig on table. The high power diode laser of $8 \mathrm{~kW}$ maximum power, 970-1070 nm wavelengths and $60 \mathrm{~mm} \cdot \mathrm{mrad}$ laser beam parameter product (BPP) was utilized in this study. The laser beam was delivered by an optical fiber and focused on the specimen surface, and the spot size of a laser beam was about $8 \times 8 \mathrm{~mm}$ at the focal point. The laser beam was directly irradiated on the surface of metal surface lap sheets under the joining conditions of the laser power controlled by coaxial pyrometer in real time. During the bonding process, the surface temperature of the specimen and the controlled laser output were monitored in real time. The traveling speed is fixed as $5 \mathrm{~mm} / \mathrm{s}$ with the defocused distance of $0 \mathrm{~mm}$. Mechanical properties of CFRP-metal laser direct joints were evaluated using tensile shear test. Microstructural characteristics of the joint zones were investigated with optical microscope and scanning electron microscopy (SEM).

\section{Results and Discussion}

\subsection{Necessity of control laser output power through temperature measurement}

CFRP is lightweight and has excellent characteristics such as high strength (5-10 times of iron), high corro- sion resistance and high fatigue property. Because it is used, it is currently used in various industrial fields. On the other hand, CFRP products are difficult to finish the final product shape, so processing technology is necessary ${ }^{7-9)}$.

In general, adhesive bonding is widely used but there are environment problem and takes a longtime to complete the bonding. Mechanical fastening such as bolting and riveting is also a commonly used technique. However, design freedom is limited and additional processing is required. As the one of solution LAMP joining (laserassisted metal and plastic joining) has been studied by many researchers. Katayama and Jung have been conducting CFRP direct bonding studies using lasers system and evaluated the weldability with stainless steel and aluminum alloy ${ }^{1-5)}$. They derived appropriate laser processing conditions from advanced study. But as

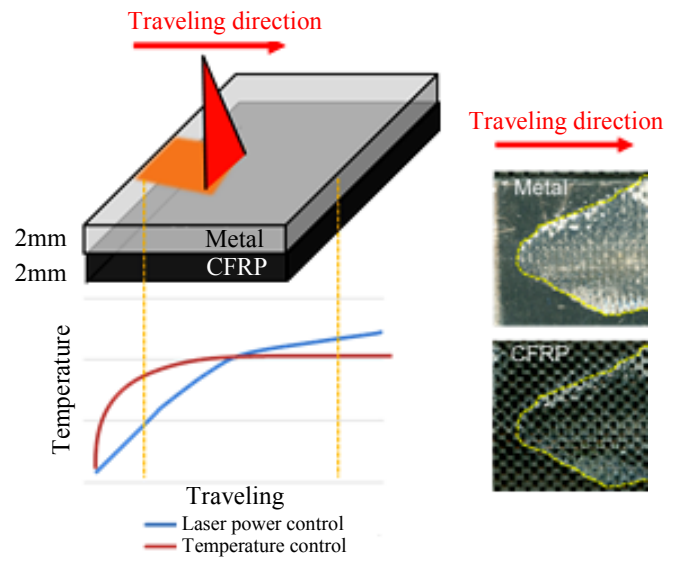

Fig. 5 Simplified graph of surface temperature and photographs of the fracture area of the joint with constant laser power 


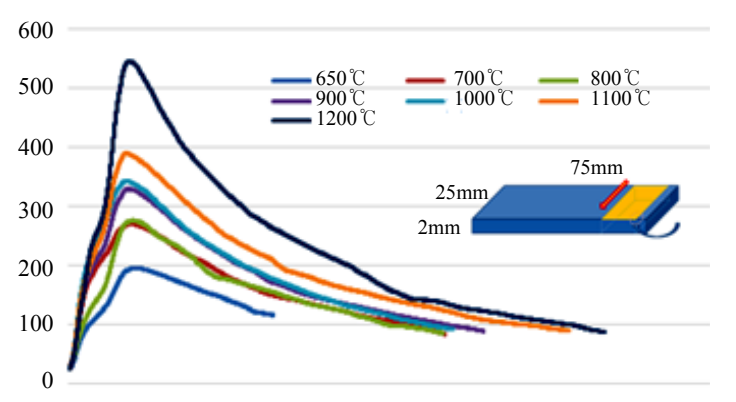

(a) Lower metal temperature gradient with upper surface temperature control

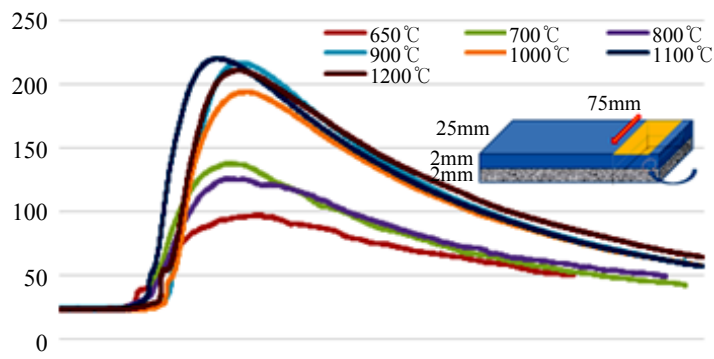

(b) CFRP (lower plate) lower temperature gradient with upper surface temperature control

Fig. 6 Results of each material temperature measurement in the upper metal material surface temperature control

shown in Fig. 5, it was observed that the joint area was changed by heat accumulation according to the travel-ling direction. As the movement progresses, the joint area increase by heat accumulation. It was difficult to obtain a uniform bonding strength because a part where bonding was not made or overheated was confirmed as indicated by Fig. 5 graph.

It is considered that maintaining the surface temperature of the specimen more uniformly than the bonding by the constant laser power condition will obtain the excellent bonding strength by making the temperature of the bonding part very uniform. The temperature of the junction between the polymer material and the metal material was measured by controlling the temperature of the upper metal surface in real time. Fig. 6 shows results of each material temperature measurement in the upper metal material surface temperature control. It is considered that proper bonding temperature is maintained at the bonding interface at the surface temperature of $650{ }^{\circ} \mathrm{C}$ to $800{ }^{\circ} \mathrm{C}$.

\subsection{Joining Properties of Metal and CFRP by Changing Surface Temperature}

Fig. 7 shows a photographs of the cross-section of the joint according to the surface temperature change. In this experiment, the surface temperature of the metal specimens were changed from $650{ }^{\circ} \mathrm{C}$ to $1200{ }^{\circ} \mathrm{C}$. As shown in the figure, cracks generated in the CFRP part at $900{ }^{\circ} \mathrm{C}$

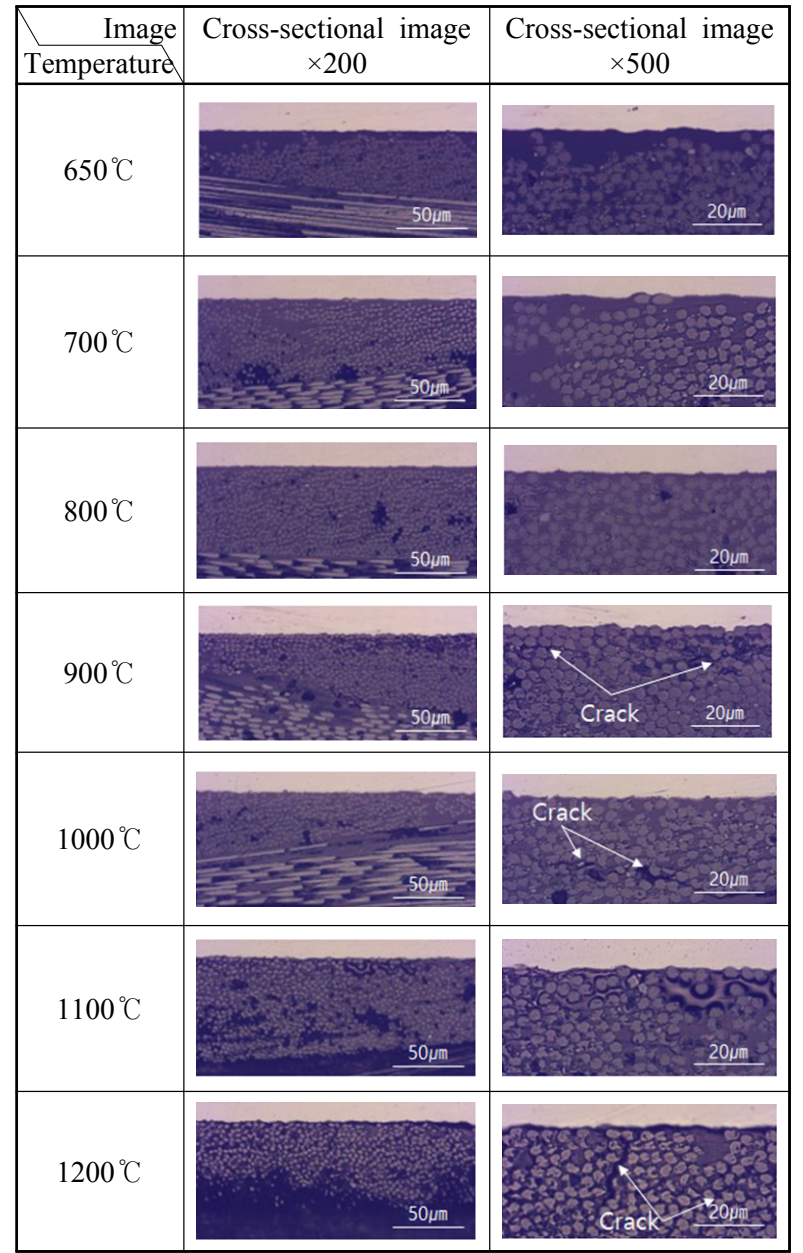

Fig. 7 Photographs of cross-sectional observation of CFRTPmetal LAMP joint by changing surface temperature

or higher surface temperature. The tendency of cracking of CFRP material due to overheating is stronger increases with increasing temperature. It is also confirmed that the thickness of the polymer layer existing at the interface between the metal and the CFRP junction also decreases as the temperature in-crease. As shown $1200{ }^{\circ} \mathrm{C}$ case, large cracks generated and there are empty spaced interface zone.

In order to clearly observe the tendency of the change of joint material behavior with temperature increase, the selected conditions were analyzed using SEM in Fig. 8. Polymer evaporation due to overheating at $1200{ }^{\circ} \mathrm{C}$ is confirmed. This causes the bonding force to deteriorate and generates a large amount of fumes. Cracks generated around the carbon fiber are observed under the condition of $1000{ }^{\circ} \mathrm{C}$. The $800{ }^{\circ} \mathrm{C}$ condition was better than higher surface temperature, but the part that was not fully bonded to the metal and polymer joint interface was confirmed. To understand the tendency of structural behavior of the actual joint area, the peak temperature was measured using a thermocouple at the interface between the two materials where the bonding 


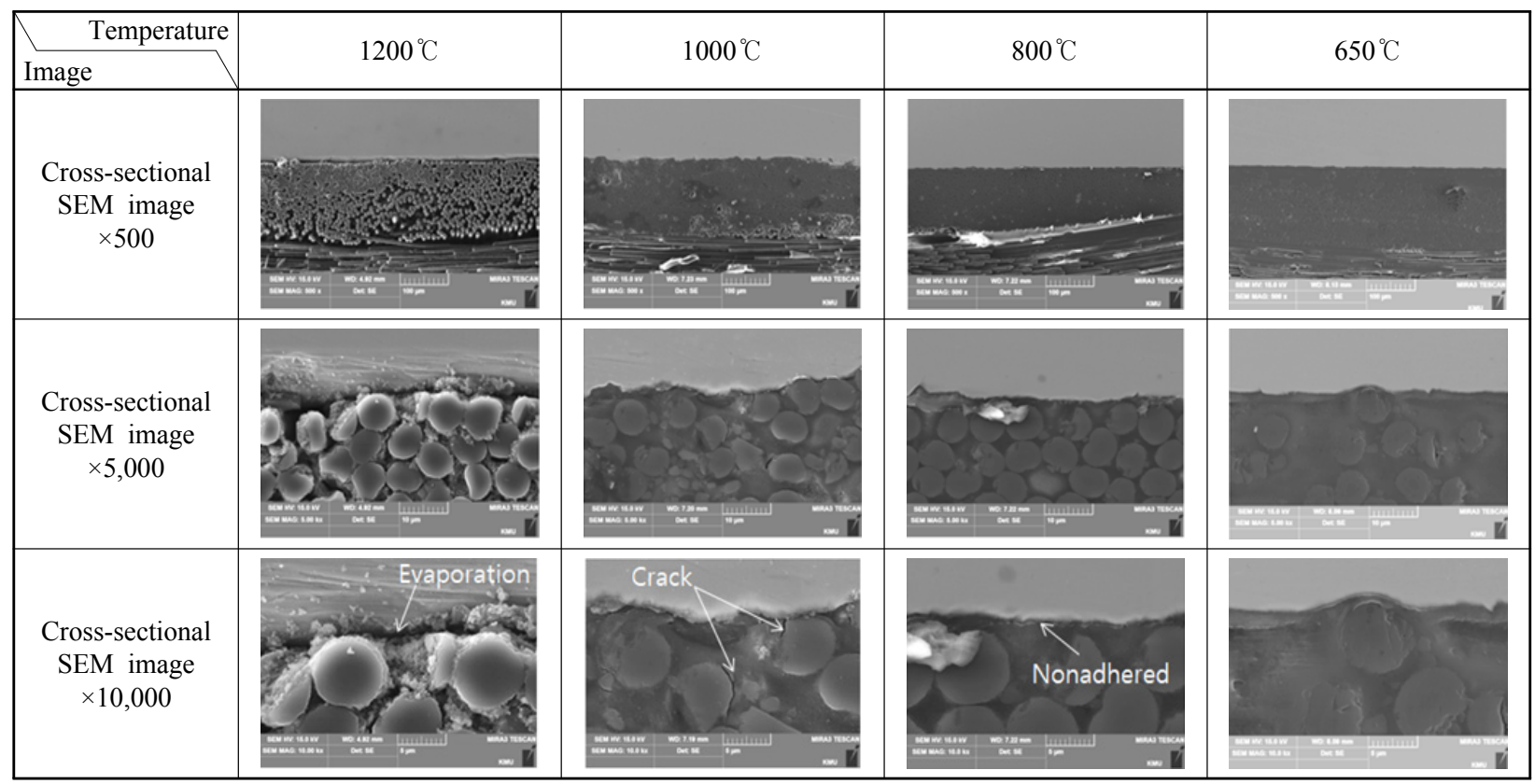

Fig. 8 Cross-sectional SEM images of CFRTP-metal LAMP joint by changing surface temperature

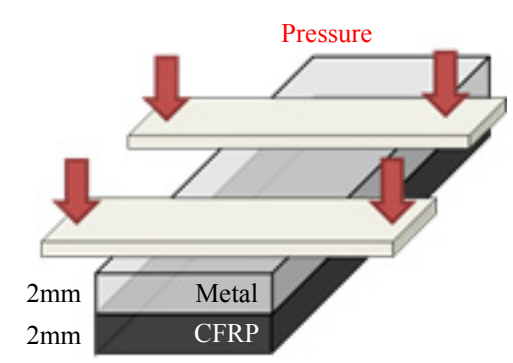

(a) Schematic diagram of concept
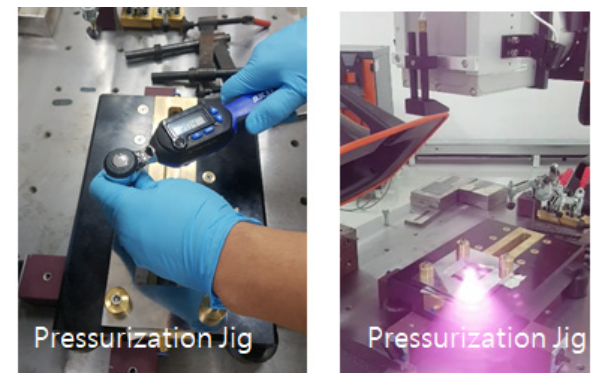

(b) Experimental photograph

Fig. 9 Schematic diagram and experimental photograph of constant load pressure jig for CFRTP and metals LAMP joining

mechanism occurs. The range in which higher than $\mathrm{Tg}$ temperature $\left(145^{\circ} \mathrm{C}\right)$ of the polymer and not exceeding the Tm temperature was $650 \sim 700{ }^{\circ} \mathrm{C}$. According to the experimental results, the optimum condition was selected that the surface temperature Fig. 8 Cross-sectional SEM images of CFRTP-metal LAMP joint by changing surface temperature was $650{ }^{\circ} \mathrm{C}$ which was $200{ }^{\circ} \mathrm{C}$ of actual joint area.

\subsection{Laser Direct Joining Properties of Metal and CFRP by Changing Press Force}

The surface temperature of the metal specimen was fixed at $650{ }^{\circ} \mathrm{C}$, and the pressure was changed by changing the pressing force of the CFRP and the metal using a special jig. A conceptual schematic diagram and a real photograph of the constant load pressurizing jig used are shown Fig. 9. It can press uniformly at constant force.

Before this study, it was expected that the bonding strength would increase as the pressing force increased. Because the adhesion and the anchoring effect are increased by stronger pressing force. Results of tensile shear test of CFRTP and metal LAMP joint by changing jig press force is graphed in Fig. 10. The shear test was carried out five times for each condition, and three averages except the lowest and highest results were cal-

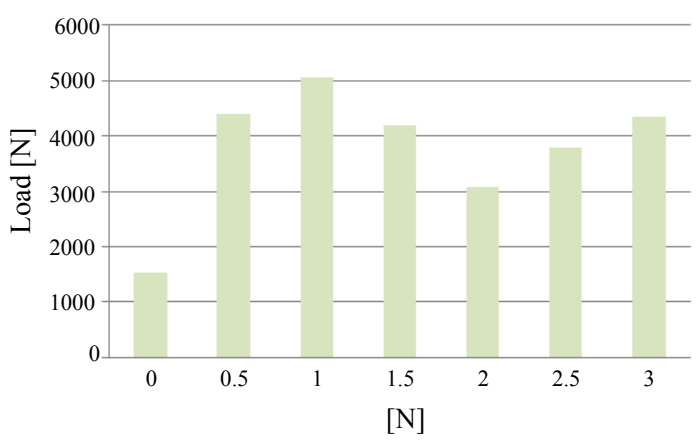

Fig. 10 Results of tensile shear test of CFRTP and metal LAMP joint by changing jig press force 


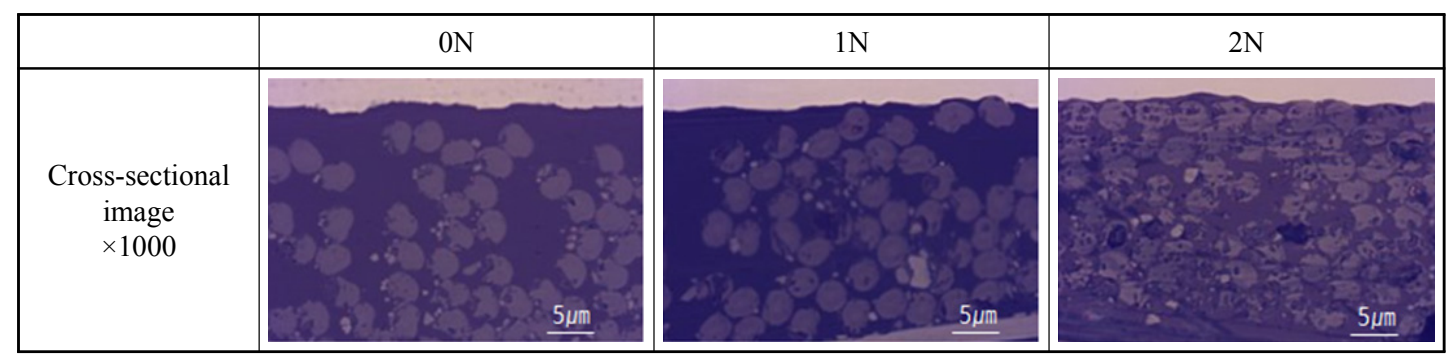

Fig. 11 Cross-sectional images of CFRTP-metal LAMP joint by changing jig press force

culated and the results were presented graphically. The load is increased up to $1 \mathrm{~N}$ jig pressure condition and then descends by $1 \mathrm{~N}$ to $2 \mathrm{~N}$ jig pressure condition.

Condition of $1 \mathrm{~N}$ pressing force has strongest tensile shear load. An interesting experimental result was obtained and the cross section of the joint was observed to confirm the mechanism. Fig. 11 shows is a cross-sectional photograph of the joint interface of selected joining conditions to understand the joining tendency. Even at the same temperature provided, it is confirmed that the polymer layer on the bonding interface becomes thinner as the pressing force is increased. In addition, at high pressures environment, some carbon fibers seem to be squeezed.

The following hypotheses were derived based on the above experimental results. The anchoring effect and the narrowing distance between the atoms is advantageous to pressurize during bonding, But it is consider that the polymer extrude outside by excessive pressure which make lower strength of joint. It is hypothesized that the phenomenon that the bond strength decreases and then partially increases is due to the polymer present in the next layer acting as a bonding agent. Further research will be conducted to confirm the hypotheses derived from this study.

\section{Conclusions}

The process of melting plastic surface of CFRTP with-out melting metal surface was studied using high power diode laser. Particularly, the surface temperature of metal was measured by pyrometer during processing and studied the joining property according to temperature change while maintaining almost constant temperature through laser output control in real time. As a result of analysis the temperature of the junction area and material properties, it is possible to produce sound bond at the surface temperature of $650 \sim 700^{\circ} \mathrm{C}$.

The surface temperature of the metal specimen was fixed at $650{ }^{\circ} \mathrm{C}$, and the pressure was changed by changing the pressing force of the CFRTP and metal using a pressurization jig. The best bond strength was obtained at $1 \mathrm{~N}$ condition at $650^{\circ} \mathrm{C}$ surface temperature, as results of applying constant pressure to the joint. The anchoring effect and the narrowing distance between the atoms is advantageous to pressurize during bonding, But it has to consider that the polymer extrude outside by excessive pressure, because it makes lower strength of CFRTP and metal LAMP joint.

Further research will be conducted to confirm the hypotheses derived from this study.

\section{Acknowledgments}

This work was supported by Carbon industry foundation creation projects(code:10083614) of KEIT (Korea Evaluation Institute of Industrial Technology), and creative-seed project(NK215F)of KIMM.

ORCID: Su-Jin Lee: https://orcid.org/0000-0002-0477-7568

\section{References}

1. S. Katayama and Y. Kawahito, Laser direct joining of metal and plastic. Scr. Mater, 59 (2008) 1247-1250. https://doi.org/10.1016/j.scriptamat.2008.08.026

2. S. Katayama and Y. Kawahito, Laser direct joining carbon fiber-reinforced Plastic to stainless steel, Industrial Laser Solutions, (2014).

https://www.industrial-lasers.com/welding/article/16484871/ laser-joining-carbon-fiberreinforced-plastic-to-stainlesssteel

3. S. Katayama, Laser joining of metal and plastic, Industrial Laser Solutions, (2010).

https://www.industrial-lasers.com/welding/article/16485092 laser-joining-of-metal-and-plastic

4. K.W. Jung, Y. Kawahito and S. Katayama, Laser direct joining of carbon fiber reinforced plastic to stainless steel, Sci. Technol. Weld. Joi. 16(8) (2011) 676-680. https://doi.org/10.1179/1362171811Y.0000000060

5. K.W. Jung, Y. Kawahito, M. Takahashi and S. Katayama, Laser direct joining of carbon fiber reinforced plastic to aluminium alloy, J. Laser Appl. 25(3) (2013) 032003. 
https://doi.org/10.2351/1.4794297

6. A. Caldwell, Polymer and Ceramic Processing, (2015). https://slideplayer.com/slide/4235773/14/images/19

7. J. G. Cho, J. S. Koo and H. S. Jung, A lightweight design approach for an EMU carbody using a material selection method and size optimization, J. Mech. Sci. Technol. 30 (2) (2016) 673-681.

https://doi.org/10.1007/s12206-016-0123-8
8. J. W. Park, C. D. Cho, S. S. Cheon and J. U. Cho, A study on fracture behaviors of aluminum and CFRP jointed with pin, J Mech. Sci. Technol. 32 (8) (2018) 3617-3623. https://doi.org/10.1007/s12206-018-0713-8

9. N. S. Ha, T. D. Dao, N. A. Goo, J. Kwak and S. Chung, Adhesion strength characterization for different frame materials of handheld products, J. Mech. Sci. Technol. 31 (10) (2017) 4795-4804.

https://doi.org/10.1007/s12206-017-0927-1 